\title{
Beyond Nativism: Reflections on Methodology and Ethics in the Study of Early China
}

\author{
Martin Kern
}

\section{Complementing or Questioning Traditional Knowledge and Authority?}

In the study of Chinese antiquity, ours is a time of great excitement: a rare historical moment of tectonic shifts in knowledge, where we feel the ground under our feet moving in unpredictable ways, and where the thrill of new discoveries is paired with uncertainty and, indeed, anxiety. Our work today is comparable in significance to the foundational commentaries from the Han that established the textual tradition, the monumental scholastic summation from the early Tang, the philosophical rethinking from the Song, the systematic philological examination from the Qing, and the vigorous critiquing of antiquity from the early twentieth century.

Thanks to Chinese archaeology - but, sadly, also to the looting and illegal selling of ancient artifacts, including manuscripts - today we work with an ever-growing body of newly discovered materials unknown to previous generations. Suddenly, we face some of the actual remnants of an ancient textual world. We see not merely early texts stripped bare of the layers of later commentary: we see different texts as they existed prior to the scholarly activities of collecting, editing, compiling, ordering, analyzing, and commentating that had shaped and reshaped these texts over time. And yet, we cannot naively claim to have access to the "original" texts of the Chinese tradition: we do not know how to contextualize the newly discovered manuscripts in their own time, and more profoundly, we must stop reading them in a hermeneutical teleology that essentializes "the original text" as an independent, pre-commentarial entity. Instead, the manuscripts teach us that the text itself was often only constituted, or re-constituted, through the transformative appropriation of commentary.

Through which methodologies shall we then try to understand these textual artifacts? Is it even possible to read a pre-imperial text strictly without its early imperial commentaries, as the glosses in these commentaries provide our 
most authoritative lexical definitions of the graphs and words in question? How can we read such a manuscript text independently from the commentarial and lexicographical tradition that from its inception involved the wholesale interpretation and rewriting in the emerging standardized script of the imperial state, the reorganization of the textual content, and the definition (or redefinition) of the very words that constituted the text proper? What kind and degree of agency do we assign to the imperial state with its new institutions of learning designed to appropriate the pre-imperial textual past? And, most fundamentally: should we use the newly discovered texts to complement the tradition as we know it, which itself is an interpreted artifact of cultural memory? Or should we use them to question that very tradition? When in 1925 Wang Guowei 王國維 (1877-1927) proposed his "method of twofold evidence" (erchong zhengjufa二重證據法), he did not advocate a merely affirmative use of archaeology to "complement" (buchong 補充) or vindicate the textual tradition. Instead, he spoke of a critical principle of "supplemental correction" (buzheng 補正), just as Chen Yinke 陳寅恪 (1890-1969), in his further elaboration on Wang's "method," used the terms "explanatory verification" (shizheng 釋證), "supplemental correction," and "evidential verification" (canzheng 參證). However, Wang — an ardent nationalist—pushed well beyond the evidence of newly discovered texts (that at his time were still extremely limited in scope):

From these materials, my generation has obtained with certainty the evidence to supplement and correct the materials on paper, and we can further prove certain parts of the ancient writings to be true records entirely.... Even books for which we have not yet attained proof, we cannot subject to denial; and for those that have already been proven, we can state categorically that they must be considered confirmed. (Wang Guowei, Gushixinzheng 古史新證)

How can one argue that because some ancient texts, or just parts of some ancient texts, have been validated, all received ancient texts should prima facie be considered reliable witnesses of their purported time? Today, much is at stake for those Chinese colleagues who feel the responsibility of protecting and carrying the hallowed tradition forward to future generations. This conviction is not to be taken lightly. As humanists, we are critical readers of texts past, but we also are their curators. Thus, in a scholarly tradition that views itself as continuous over millennia - a continuity created from layers of retrospective construction-modern Chinese scholars might see themselves as the intellectual descendants of Kongzi. By contrast, scholars looking at China from the 
outside-people like myself - do not work under this responsibility and do not feel the same weight and demands of tradition. We are free to question everything and anything, though we are not free to do so recklessly or frivolously. We come from a European tradition that has always been polycentric and multicultural; it is not that long ago that scholars worth their salt were simply expected to be conversant in the major "European dialects." That much of Western Sinology nowadays appears as a bilingual affair-Chinese and English — is largely due to the shift of the field toward the United States, which in turn was fueled by the German emigration during the 1930s. European multilingualism in general has not done well under the depressing state of language education in the United States, but for reasons discussed below, the dominance of English in Sinology exceeds that in other fields of the humanities.

Yet regardless of the regression of academic multilingualism, Western scholars stand outside the traditional Chinese perspective that, in sharp contrast to Europe, since pre-imperial times has idealized unity as the absolute precondition for both political stability and cultural glory, despite and against the historical experiences of disunity and discontinuity that since Warring States times have repeatedly produced the richest tapestry of culture. A Western humanist may not easily share the desire to impose unity upon diversity; instead, we hold dear our differences and cherish — with pride refracted through self-irony_our idiosyncracies even within our many countries. The ongoing Chinese debate over "doubting" or "trusting antiquity," concerned with contemporary identity and claims for an unbroken continuity with antiquity, only bewilders people like me. And yet, our field cannot simply divide the labor between Chinese curators and non-Chinese critics. Just as Li Ling 李零 from Peking University has noted, "scholarship has no ancient or modern, Chinese or foreign [or “inner and outer"]” (xue wu gujin zhongwai 學無古今中外). Our responsibilities as both curators and critics are shared, or we may go our separate ways and abandon all pretense regarding our shared historical endeavor.

We would miss a fabulous opportunity. For the first time in history, China is concurrently studied by scholars around the globe, all of them anchored in their own traditions, and all potentially responding to one another. This leads to moments of frustration: we can find it difficult to respect premises we do not share. But the experience of alterity and distance is not a problem: it is a perspective and it is a promise as long as we are willing to recognize strengths that are not our own. No Western scholar can hope to match the rich intuitive understanding of Chinese texts that defines the very best of Chinese work. But our initial disadvantage can quickly turn into strength, as can be seen in translation and systematic textual analysis: the best Western translations and 
studies are based in rigorously analytic methodology because we cannot simply "translate" the graphs of a classical Chinese text into the identical ones of a modern text (quietly suggesting the identity of the classical and modern words written by them, a problem also pervasive in Japanese translations). Instead, we must make precise decisions that no modern Chinese reader needs to make, and only in making these decisions do we realize their importance. The foreign scholar faces questions that the text itself has never asked but that nevertheless must be answered in order to understand the historical specifics of cultural practice and knowledge represented, however imprecisely, in the word. Even where we cannot reach definite answers, we go through processes of analysis and methodological reflection that generate additional layers of understanding-layers we cannot unfold otherwise. We can only, and must, read slowly.

These processes of reasoning transcend translation. Yet translation illustrates and embodies how the "outside" perspective generates meaning differently, and often different meaning. For this reason, much of non-Chinese scholarship appears profoundly distinct from the learning that arises from within the tradition. The insistence on methodology is itself a clear sign of an "outside" perspective, but this does not mean it can only come from the outside. To the contrary, just as no "outside" interpretation can ignore the inexhaustible accomplishments of two millennia of scholarship, traditional learning must embrace methodology in ever renewed acts of self-distancing. This is the ground where all of us can meet: methodology does not displace accumulated knowledge but generates perspectives, questions, and possible answers that cannot be discovered otherwise, and that are certainly not available to a tradition that operates strictly on its own terms. In a dialectical turn, the "outside" must become part of the "inside": not subsumed or appropriated but, to the contrary, as a transformative force of internalized alterity. The "inside" cannot remain an unreconstructed "inside"; and likewise, the "outside perspective," in an eternal feedback loop, is continuously informed and reshaped by whatever "inside" phenomena it is meant to illuminate, and by whatever "inside perspective" it tries to respond to.

It should be clear that however alien some of the thoughts expressed in my own work may sound to the consummate cultural insider, they are meant to contribute new possibilities of understanding to our common project. What is more, my perspective is not just that of a China scholar looking from the outside in. I talk as much to colleagues in fields like Classics and Comparative Literature as I talk to fellow Sinologists, and I try to read as much on antiquity in general as I do on Chinese antiquity in particular. These wider 
cross-disciplinary and cross-cultural experiences are transformative. Global humanistic scholarship is not bipolar, with Chinese and non-Chinese scholars looking at China in different ways; instead, it is multipolar, with China being one subject among many. Just as I "look in" on China, a colleague in Shanghai may "look in" on ancient Greece, India, or Egypt, and we both then "look in" on the global possibilities of antiquity altogether where "our own" part may be central but only as one smaller part of the much larger whole. This is why comparative knowledge and perspective are indispensable: by offering alternatives to the specific choices each ancient culture has made for itself and has considered self-evident ever since, cross-cultural comparison helps all of us to defamiliarize the familiar, be it in China or anywhere else.

In the globalized study of China today, we can cooperate much more efficiently because of the availability of electronic resources. The major Chinese and foreign institutions subscribe to powerful databases that make our scholarship readily available online. There is no excuse not to be aware of recent Chinese journal articles; and while the situation in China beyond Beijing and Shanghai is not yet comparably convenient, Chinese scholars have various institutional and personal ways to get access to foreign scholarship. (Strangely and regrettably, the exception is Japan; there is no Japanese online infrastructure to provide full-text scholarly articles.)

The digital humanities are rapidly transforming our access to original texts. All known ancient Chinese writings, including recent paleographic materials, have been digitized and are easily available to, and searchable by, every scholar of ancient China. With the press of a button, we can now search the entire Chinese written tradition at a scale and speed far beyond the memory of the most learned eighteenth- or nineteenth-century scholar. On my phone, I can within seconds look up a word in the Hanyu dacidian 漢語大辭典, the Grand Ricci, the Oxford Chinese Dictionary, and the new Student's Dictionary of Classical and Medieval Chinese all at once, plus some others. Meanwhile, as our databases are getting "smarter" by the day, we can detect literary patterns and perform "fuzzy" linguistic searches and analyses that were unimaginable with the printed concordances of old. In our classrooms and at academic conferences, we can instantly pull up both classical sources and their modern scholarship — and if we don't do it, our students most assuredly will. Technology has thus leveled the field in all directions. While no database search can replace the slow reading of entire texts, to "know texts" and, most importantly, to find connections among an infinite number of texts, now takes on entirely new forms. As we all can discover textual patterns and relationships across the entire body of ancient Chinese writing, the formerly vast advantage enjoyed by a Chinese scholar who had started memorizing the classics in elementary school 
has shrunk dramatically. Digital competence has its own limitations and problems, and is not the same as the accumulation of knowledge, but it is now an incredibly powerful tool for methodology- and data-driven analytic research, that is, scholarship much less dependent on traditional learning.

Taken together, new sources, new methodological approaches, and new technologies are rapidly transforming what we study about ancient China and how we study it. No enterprising student today is confined to the printed resources I had available when writing my dissertation, and as a result, our students can chart paths of study that were impossible to even imagine just a few years ago. Some of these paths lead to surprising discoveries that unsettle received wisdom, but we should embrace the spirit of letting go of traditional beliefs and false certainties that with every passing day are getting a little bit more difficult to cling to. The exacting philology devised by the great scholars of the eighteenth and nineteenth centuries is still important, but it no longer dominates critical inquiry to the degree it once did. Now placed into dramatically wider horizons, many of its basic assumptions are again thrown into the open. Likewise, the linguistic analyses of mid-twentieth century giants like Wang Li 王力 (1900-1986) and Bernhard Karlgren (1889-1978) were the best of their time, but their time is over. One reason is the development of much more refined analytical instruments; another is the discovery, in epigraphic sources, of much more diverse linguistic data. Significant parts of what seemed settled fifty years ago are no longer certain. Yet while we already have enough new evidence to question the old orthodoxy, we do not have nearly enough to establish a new one-nor do we need one. Ours is an exciting time of Socratic insight where new knowledge only reveals how little we truly understand.

\section{A Dead End: The New Traditionalism and Fundamentalism}

When speaking, one should know one's audience: what it expects and takes for granted, what it holds as true and what it will not accept. Yet as a foreign scholar speaking on China in China, I resist its nativist discourses. The most powerful of these discourses is captured in the late Li Xueqin's 李學勤 (1933-2019) enormously influential claim, first advanced in 1992, that the study of ancient China has now reached the time of "walking out of the age of doubting antiquity” (zouchu yigu shidai 走出疑古時代). While Li's book of the same title offered a sophisticated analysis that did not reduce early China to simple truths, his slogan-appropriated by others to advance claims far beyond Li's original position-has become the new Chinese orthodoxy. At conference after conference, it is now routinely called upon to "prove" (zhengming 證明) the true 
antiquity of whatever later tradition claims as such, and to silence uncomfortable questions.

"Walking out of the age of doubting antiquity" is typically concerned with proving the authenticity of transmitted texts. It explicitly rejects the indigenous "doubting antiquity" (yigu 疑古) discourse of the 1920 s and 193 os where scholars led by Gu Jiegang 顧頡剛 (1893-1980) and others subjected the texts from Chinese antiquity to radical questioning. The "doubting antiquity" movement was itself nationalistic as it tried to attack the foundations of traditional learning in order to build a new intellectual basis for the emerging post-imperial, post-traditional Chinese nation-state. Today, the attacks on "doubting antiquity" reflect the radical ideology of rejecting modernity itself: the rejection of the project that recognizes the unbridgeable gulf between the distant past and its modern interpreters. In contrast to "doubting antiquity," the powerful movement of "walking out of the age of doubting antiquity" reflects a premodern mind that insists on a mythological, idealized past that cannot be questioned, and where tradition must be taken as literally "true" as long as it is not "proven" otherwise. In suspending the critical facility of probing questions that are not a priori geared toward a desired result, prominent scholars have taken their place within the hallowed tradition instead of assuming a selfreflective distance to it. Their ideology has not emerged by coincidence: two generations after the end of the "century of national shame" (bainian guochi 百年國恥), i.e., China's military and political humiliation by Western and Japanese imperialists, and a generation after the anti-traditionalism of the Cultural Revolution, it marks the needs of a newly rising China. Intellectually, this new China is a China without recent history - as if eager to prove Hegel right after all, it connects back to nothing but a set of timeless beliefs about antiquity, represented by a revered "Confucius" and similar icons. Historically, "walking out of the age of doubting antiquity" is the answer to the Cultural Revolution of the 196os and 1970s, the "doubting antiquity" movement of the 1920s and 1930s, and the collapse of the traditional empire. There is thus no modern intellectual tradition that current Chinese scholarship can (or is willing to) claim as its foundation. This is the problem contemporary traditionalism seeks to resolve, and does so exclusively on premodern Chinese terms. Furnishing the ideological underpinnings of a new China, the embrace of antiquity has little use for non-Chinese ideas: it insists on a Chinese monopoly on interpreting China. Instead of embracing the rich tapestry of antiquity that includes China, its neighbors, and other civilizations, and instead of valuing scholarship from abroad, those who define their own cultural identity on purely Chinese terms routinely deploy three tactical moves: first, while paying obligatory lip service to foreign scholarship, they rarely ever read any of it; second, they do not learn 
any foreign languages; and third, they show no interest in other ancient cultures, or in the highly inspiring study of these cultures. The result is a body of scholarship that is defensive, nativist, self-marginalizing, monolingual, and monocultural. Looking toward the future, I find it difficult to see how such scholarship can continue to succeed even for one more generation.

An example of how this plays out is a paper for which I served as commentator at a conference in Beijing. The paper was designed to "prove" that certain parts of the ancient Classic of Odes and Classic of Documents constitute part of "Shang dynasty literature," pushing these texts back by centuries to a time from which no other works of comparable language, size, or type are known. Such a claim would not have been acceptable for at least the last hundred years but is now advanced by reference to new archaeological evidence. Recent archaeology has indeed produced a wealth of data that teach us much we did not know before-though literally nothing about "Shang dynasty literature." However, the mere general reference to archaeology, echoing Wang Guowei's claims cited above, provides broad rhetorical coverage under the umbrella that in general archaeology can now be used to refute any positions associated with the earlier "doubting antiquity" movement. Thus the argument for "proof" is simply reversed: "since archaeology has now proven so many things, how can you disprove that something is as old as I claim it to be?" I cannot, of course, because quasi-religious beliefs, as opposed to scientific hypotheses supported by explicit evidence, are not open to be disproven.

The new traditionalism is not merely about proving the age of classical texts. It operates on simplistic assumptions that "earlier" means "better," "more reliable," and "more true," all the way to the deeply held but obviously fallacious belief that texts must be contemporaneous with the events they describe, and spoken by the historical actors to whom they are attributed. Such assumptions may be considered hopelessly naïve; they may be called implausible in the extreme; by a very large margin, the preponderance of evidence may speak against them; but they cannot be disproven. And thus, the traditional speech attributed to the ancient Shang king Pan Geng 盤庚 becomes a Shang speech. It does not help to protest that no evidence exists for the language and rhetoric of the Pan Geng speech during the Shang. "How can you say it did not exist? The proof is right here!" Related to such arguments is the willingness to accept any later source, even if it postdates the matter in question by a millennium or more, as "evidence." The question then turns to what counts as proof, and whether rules of argument and evidence are universally agreeable. If not, then no scholarly dialogue is possible. For perspective, how would we judge Biblical scholars using a random selection of medieval European writings as "evidence" to "prove" something about the earliest layers of the Hebrew Bible? We would 
not be able to disprove them, but perhaps we would ask them a question: "Why is this so important to you?"

At stake is not so much the validation of three millennia of textual tradition but a fundamentalist belief about the origins of that tradition. Perhaps one may choose to participate in "proving” Chinese antiquity, but I won't, nor do I think it has any future in the global humanities. We cannot apply one set of "critical" modern methodological principles to ancient civilizations around the world, and then have a second "faithful," premodern set of principles that applies only to China (and some other places where scholarship is pursued as the practice of faith). The latter does not have a passport and cannot travel. Its relevance ends at the border.

A vision of Chinese antiquity that does have such a future in the global humanities, and that could help us to correct the still pervasive Western idea of antiquity as simply Mediterranean, can only be one that foregoes claims of Chinese exceptionalism and instead participates in comparative discussions with other academic fields as they are pursued outside of China: Classics, ancient history, archaeology, anthropology, comparative literature, and so on. No ancient civilization is most productively interpreted through faithful devotion or within the confines of the particular academic tradition it has engendered over time. All of them benefit from an awareness of the ancient world broadly conceived, as comparative research frequently opens prospects that are not overtly suggested by the material specific to any place or time. The famous dictum by Max Müller (1823-1900), Professor of Comparative Philology at Oxford University, that "He who knows one [religion], knows none" remains our most productive guide, including for those scholars who study "their own" culture and history. Only the non-nationalistic, non-exceptionalist study of Chinese antiquity that opens itself to comparative questions and perspectives is one that can succeed globally, and that may challenge the Eurocentric hegemony over the study of the ancient world. In studying China, those who reject comparative thinking are not doing their own field, or their students, a favor.

Fortunately, there is some hope. Today a number of major Chinese universities are beginning to build departments of Classics, Egyptology, and so on, and no few foreign specialists have been invited to China to share their knowledge and provide inspiration. We should welcome this exciting prospect: just as the study of Chinese antiquity has much to gain from dialogue and cross-cultural comparison, the study of the ancient Mediterranean and Near Eastern world can benefit enormously from the engagement of scholars informed about China. To date, a field like Classics - institutionally configured, in one way or another, around the study of ancient Mediterranean and Near Eastern history, philosophy, literature, archaeology, and religion, but often even more narrowly 
concentrated on just Greece and Rome-easily dominates any thinking about antiquity in the West. As that field now gradually develops at the best Chinese universities in mutual exchange with the study of Chinese history, literature, archaeology, and philosophy, I suspect that we all will be better for it.

\section{Essentializing Discourses: “Sinology” versus "National Learning”}

It is not my goal to deny the validity of traditional claims, or to align myself with a particular scholarly movement of the past. Writing from the American East Coast, I am not personally invested in discourses that answer the needs of Chinese cultural and political identity. My own identity as a scholar is grounded in forms of inquiry that expose my assumptions and biases as transparently and self-critically as possible. This is not only a method but also a meta-method: to the faithful, the principles of critical inquiry are in themselves partisan and oppositional.

On the other hand, rigorous critique is not a license to run roughshod over the traditional views that have formed through millennia of traditional scholarship. Without this scholarship since the Han dynasty (2O2 BCE-22O CE), our understanding of ancient texts would be incomparably poorer. Powerful traditions endure for good reasons and their accomplishments deserve profound respect. To some extent, though bent by ideologies and institutions, the survival of scholarship follows a Darwinian logic: that we can still access explanations from very early periods means that they have been considered plausible and worthy of transmission ever since. Unless we can show how our judgment surpasses that of our predecessors, we should not lightly abandon their convictions, especially since ancient and medieval scholars worked with a wealth of historical materials long lost to us. We must ask, however, how their exploits hold up to critical reasoning that places methodology above identity and inquiry above acceptance. In this, all contemporary scholars, Chinese or not, are looking at antiquity from the outside in: we all are foreigners to the ancient lands and must acknowledge the fundamental remove that defines our position. This remove of two millennia is far greater than the distances between contemporary cultures or languages. Regardless of our identities, we all have more in common with one another than any of us has with the ancients. This becomes obvious in anachronistic projections of our own assumptions into antiquity. Especially for a native scholar, the appeal of such projections lies precisely in their seeming naturalness. An ancient Chinese graph is easily misread in its modern meaning even though that meaning had entered the Chinese language only recently, often from Japanese. Thus, wenxue 文學 in the 
Confucian Analects does not mean "literature"; it means "the learning of cultural patterns." Modern Chinese is not helpful here.

In my academic exchanges, I find myself talking to (a) academics working on China within China, (b) those in Europe and North America (and to a far lesser extent also Japan) working on China, and (c) those who specialize in other fields such as Comparative Literature, Classics, Near Eastern Studies, and so on. Each time, I find myself addressing a discursive field not merely separate but radically different from either one of the other two. Far more often than not, local scholars in China are only concerned with China and feel perfectly justified to read only Chinese scholarship; and likewise, most American and European humanists who know nothing about China seem entirely at ease that way. As I try, separately, to converse with both, the ways in which I present my work are asymmetrical and mutually incompatible. What makes sense to one group of learned scholars can make no sense whatsoever to the other.

Of course, "Western scholars" - including Chinese scholars based at European and North American institutions - in my field all realize that they operate in separate discourses and hence speak in different idioms, depending on whether for Western or Chinese academic audiences. This is true particularly with audiences in Mainland China where departments especially of Chinese language and literature can be decidedly nativist and inward-looking, and where the study of China is a monocultural, monolingual affair with little use for outside perspective. This is not true of all such departments across Mainland China, but it is overwhelmingly the rule. Not too long ago, I experienced the following at a conference in Beijing: in the session I happened to chair, a senior professor from a major Chinese university admonished a younger colleague that his way of analyzing a text was not right; it was something one could accept from a foreigner, but not from "us Chinese" (women Zhongguoren 我們中國人). Without a second thought—but then visibly embarrassed when I joked about it in response-he insisted on the separation of our discourses and made it clear which side of the gap he considered the right one. His strategically deployed essentialism and uncontained sense of superiority shielded him from "foreign" readings of "his" traditional Chinese texts. Meanwhile, put firmly in his place within the local hegemonic discourse, the young assistant professor was reminded that he was still one of "us Chinese," not "them." And in some sense his senior colleague was not entirely wrong: our different readings often reflect strikingly different sets of questions, interests, and motivations, and within the confines of our communities and academic institutions, these cannot be taken lightly by a young scholar standing early in his or her academic career. The risks of looking like "one of them" are enormous, while the possible rewards for even considering "their" readings are negligible. 
The distinctions I have introduced so far are, however, somewhat crude: they catch some but not all of reality. Hegemonic discourses exist everywhere, from the powerful cultural and academic influence that the rest of the world recognizes in contemporary U.S. American scholarship to the nativism of certain Chinese scholars who are not shy to express their disdain for non-indigenous thought. But in the learned communities I travel in, there also are scholars who-for better or worse- defy the expectations of their own academic communities, even to the extent that they live and teach in one community while adhering to the ideological norms of another one. This is not a question of race or ethnicity. There are, of course, numerous Chinese scholars working at European and North American universities, where they function smoothly according to local expectations; there are Chinese scholars who take up positions at universities in China after having received their doctoral degrees in the West; there is a growing number of Western scholars who hold appointments-regular or honorific - at Chinese institutions; there are Western scholars teaching at U.S. institutions who subscribe to the traditionalist Chinese agenda; and there are Chinese scholars teaching in China who push the limits of Western theory. We all overlap in interesting ways and share ample opportunities for both inspiration and frustration. These experiences easily cross disciplinary and cultural boundaries, and they subvert the fields and identities we construct for ourselves and cast into terms like "Sinology" in the West or "national learning" (guoxue 國學) in China. And yet, these constructions are powerful.

The newly minted discipline of "national learning" in China-at major institutions a degree-awarding field now often framed as the indigenous study of the Chinese classics - by definition stands separate from "Sinology" (hanxue 漢學), a field generally defined as the study of premodern China "from the outside." But what is "the outside"? It cannot just refer to work done outside of China or to scholars who are not ethnically Chinese. A field like "Sinology" which in the West is distinguished from social science-driven "Chinese studies" - cannot be defined in terms of the national or racial identity of its practitioners or of geographical location but only by way of methodological difference. Only in this sense hanxue is "outside" and guoxue is "inside." No Chinese scholar working in China calls himself or herself a hanxuejia, or "Sinologist."

Both "Sinology" and "national learning" have complicated origins and epistemological perspectives. "Sinology" or hanxue literally means "Han studies"; the Japanese pronunciation of the term is kangaku. In Meiji Japan, the term kangaku was used for the earlier Tokugawa period study of China (with kan referring to "China"), similar to how Western scholars began to use "Sinology." Yet in eighteenth- and nineteenth-century China itself, hanxue was a branch 
of historical-philological studies that referred back to scholarship from the ancient Han dynasty in opposition to the more recent, and more philosophically inclined, Song dynasty learning (songxue 宋學). When Jesuit and other Western scholars adopted hanxue for themselves, they conflated the historical-philological orientation of hanxue with the meaning of kangaku as "the study of China," or "Sinology." Thus came about the definition of Sinology as the historical-philological study of premodern China from abroad, focused above all on the written sources from the past. In other words, the epistemological core of Sinology is both Japanese (as the study of China from the outside) and Chinese (as a particular methodology). Perhaps unsurprisingly, this kind of "traditional Sinology" is often derided as antiquarian, methodologically naïve, and generally obsolete; in its pejorative use in contemporary cultural studies or the social sciences, the word reeks of disdain.

On the other hand, "national learning" started not only as a non-Chinese term but as one opposed to Chinese learning: when Meiji period Japanese scholars in search of Japan's cultural identity rejected kangaku and its implied veneration of China as Japan's classical antiquity (and even more so "Western" studies), they promoted as an alternative "national learning” (kokugaku 國學) focused on a newly invented canon of Japan's own indigenous classics. Only in the early twentieth century, after the end of the Chinese imperial state, kokugaku - written in Chinese graphs and pronounced guoxue in Chinesewas then introduced into China to denote Chinese learning focused on the Chinese classics. Just as kokugaku as Japanese learning served the cultural and political identity of the Japanese nation-state in the nineteenth century, guoxue as Chinese learning served the same purpose for the Chinese nation-state in the early twentieth century; both were focused on the respective "national essence" (jpn. kokusui 國粹, ch. guocui) as the nativist study of one's own civilization. Today, after guoxue had been nearly forgotten in China for more than half a century, its revival serves the same purpose once again.

The convoluted histories of these words stand metaphorically for the methodological and ideological uncertainties in the study of premodern China. Both "national learning" and "Sinology" remain contested concepts: many Chinese scholars reject the "national learning" pursued and celebrated by their colleagues, while in the West, depending on whom one talks to, the designation "Sinologist" can be a badge of honor or the kiss of death. In addition, both within and outside of China, the notion of a "New Sinology" (xin hanxue 新漢 學) has been proposed, though different scholars use the term in rather different ways, just as "national learning" and "Sinology" mean different things to different people. 


\section{A Personal Reflection: Why I Must Oppose the Politics of Traditionalism}

Let me conclude with some personal reflections. Here, I only speak for myself and for the way I myself experience the academic field of early China. Others in my field-let alone those in other disciplines—have different experiences, and they certainly have different convictions. I cannot be a representative of "Western Sinology" in any way; not only are there many different "Sinologies" in "the West," but with my dual citizenship and two passports, I belong to more than one. Born, raised, and educated in Germany, I was twenty-five years old when I arrived at Peking University in 1987; I left two years later, after the trauma of Tiananmen. But it was not until January 1, 1997, that I arrived in the United States, where I have remained ever since: first for eighteen months at the University of Washington in Seattle, then for two years at Columbia University, and since then, finally, at Princeton.

Soon after my arrival in Seattle, I was confronted with the history of German and American Sinology I had not known, but which, as was clear immediately, I could not escape. At the time, I was a member of the Deutsche Vereinigung für Chinastudien (German Association for Chinese Studies) that had been founded in the Spring of 1990, just months after the fall of the Berlin Wall. In early 1997, the Association prepared its annual meeting on October 24-26, 1997, in Berlin, dedicated to the history of German Sinology, seven years after the German unification. Revising my German dissertation from Cologne University, I spent my days in the East Asian library of the University of Washington where every once in a while, I found handwritten remarks penciled into a book: traces left by Professor Hellmut Wilhelm, the German Sinologist who in 1948 had moved from Beijing to Seattle. The indirect encounter with Wilhelm sparked my interest in his life. Soon I learned that he was only one of several German or Austrian Sinologists who had ended up in Seattle during or shortly after the Nazi Regime, and who in turn made up a fraction of the dozens of scholars in Chinese studies who had left Nazi Germany, never to return.

Just as I learned about this history-which nobody in Germany had ever taught me-I received the preliminary announcement of papers for the 1997 Berlin meeting. There was nothing about the large-scale emigration in the 193 os that had completely eviscerated the field in Germany. Was this not part of the century-long history of German Sinology? Through some initial research, I then discovered an entire sequence of scholarly articles that German Sinologists - West-German Sinologists, to be precise - since 1945 had written about the history of our field. For more than fifty years, the authors of virtually all of these articles had skillfully avoided any reference to the fundamental 
rupture that had occurred, depicting instead a false continuity from the very early to the very late twentieth century. In their deafening silence about the emigration of German Sinologists, these postwar scholars exiled and erased their own predecessors from the field once again, and then again and again, in article after article. Their history of German Sinology was a lie and a betrayal.

As this shameful situation was about to repeat itself yet again, I researched and wrote the first extensive study on the emigration of German Sinologists. While for lack of funds I could not leave Seattle to join the Berlin meeting, the paper was presented in my absence. In addition to the German version, I then also wrote a more substantial one in English: my first scholarly article written and published in the United States, in the Journal of the American Oriental Society. While this article has been translated into Chinese and published in three different books and journals in China, none of my Chinese colleagues has ever mentioned reading it.

The history of German Sinology is also my own history — not just in the way one considers one's national history one's own or because I made it a topic of my research. I do believe that the flight of Sinologists from Nazi Germany continues to exert its painful influence on the present state of German Sinology. After its near-total collapse, the field never regained or developed a stature similar to other fields in the classical humanities or created a comparable number of career opportunities at German universities. No Sinologist who had fled from the Nazis ever went back. Instead, these scholars contributed greatly to the development of Sinology especially in the United States. They left behind not just a country and an academic field, but also a language: their switch to English initiated the rapid decline of German as a major academic language in our field, while their new publications strengthened the status of English, a process that also has taken its toll on other European languages in Sinology. In Chinese studies today, almost no Chinese scholars or students, and very few Americans, read German.

At the same time, the rapid development of the field in North America widened the gap. As a result, another generation of young Sinologists left Germany over the past three decades, and I am just one of them. The number of German scholars working on Chinese antiquity and holding tenured positions at universities in the United States, the United Kingdom, and elsewhere surpasses the number of those who do so in Germany. While the economic and political rise of China has led to the creation of positions on contemporary China at German universities, part of this growth has come from the conversion of former positions in classical Sinology. Berlin in particular, once the proudest place of German Sinology, is a wasteland: with some eighty thousand students at the Free University and Humboldt University, the German capital currently 
has but a single professor in the study of premodern China. (Princeton, with altogether less than seven thousand undergraduate and graduate students, has eight.)

How does all this affect my own perspective on the study of Chinese antiquity? First, I experience Sinology as a global field embodied in my biography. Second, I have learned to look at Germany from the outside. And third, for being aware of my country's history, I can never accept "tradition" in any simple, unreconstructed sense. The first two of these points give me perspective; but the last gives me identity: the identity of someone whose national heritage is always broken and fragmented, and remains powerfully present just as such. "Walking out of the age of doubting" is never an option. I viscerally reject nationalistic scholarship in the service of political and cultural identity, and I do not consider a term such as "national learning" innocent.

Sadly, some current Chinese scholarship on ancient China is driven by precisely those ideological abuses of "tradition" that deep in my heart I despise the most. Yet I also understand the desire for an unquestioned, perhaps even unquestionable, tradition in response to the vast destruction of cultural and personal identity during the Cultural Revolution's "ten years of madness." The foundational myth of the Chinese classics and Chinese scholarly identity is the story of the Qin First Emperor "burning the books and burying the scholars." Invented in the Han dynasty, this narrative resonates with scholars of traditional China who suffered in fear through the Cultural Revolution, who saw lives destroyed, and who will forever miss the education so viciously denied. In the overwhelming combination of life experienced and history imagined, scholars had to survive the Qin First Emperor just as they had to survive Chairman Mao - the man who, two thousand years later, saw himself proudly in that ancient emperor's image. Just as I cannot bear the ideological construction of tradition as something that must not be doubted, some of my Chinese friends cannot allow a radical questioning of tradition they perceive as purely destructive. They have seen the annihilation of traditional culture.

In the end, we all are scarred and scared in our own ways. Our debates over tradition can lead to moments of raw emotion. Both privately and in public responses, Chinese colleagues have spoken movingly of the unresolved trauma of the Cultural Revolution and the resulting feeling of misery. I think I can understand this. And yet, I do not believe that the false promises of traditionalism provide an answer they can sustain, or an answer that can sustain them.

Note: The present essay is revised from an earlier Chinese version published as "Chaoyue bentuzhuyi: Zaoqi Zhongguo yanjiu de fangfa yu lunli” 超越本土主義：早期中國硎究的方法與 倫理 in Xueshuyuekan 學術月刊 49.12 (2017): 95-104. 